\title{
Effect of Life Review and Cognitive Therapy on Depression in Patients with Chronic Renal Failure
}

\author{
Sutinah Sutinah \\ Harapan Ibu College of Health Sciences, Jambi, Indonesia \\ Corresponding email:ns.titin@gmail.com
}

Submitted: 02-04-2020 Accepted: 10-06-2020 Published: 01-08-2020

\begin{abstract}
Patients with chronic renal failure suffer higher rates of depression because of psychological stress due to physical and social changes. Efforts to reduce depression level are needed. Cognitive therapy and life review therapy are believed to be effective in reducing depression. The aim of this study was to compare the effects of life review therapy alone and in combination with cognitive therapy on depression in patients with chronic renal failure. This study employed a quasi-experiment with a comparison group design. Fifty-six respondents were selected using a consecutive sampling, which thirty-six were assigned in the experiment and comparison group. Depression was measured using Beck Depression Inventory. Dependent and Independent t-test were used for data analyses. The results revealed that the combination of life review and cognitive therapy had a significant effect $(\mathrm{p}<.05)$ in reducing depression compared with the life review therapy alone. The average of depression score decreased in the experiment group from 27.04 (4.71) to 22.29 (4.24). But there was no significant change in the average of depression score in the comparison group from 26.54(4.18) to 26.71 (3.70). This therapy can be used as a complementary medicine to treat patients with chronic renal failure, specifically for those with depression, and it serves as a recommendation for nursing intervention in hemodialysis units.
\end{abstract}

Keywords: Chronic renal failure, cognitive therapy, depression, life review. 
Sutinah: Effect of Life Review and Cognitive Therapy on Depression in Patients with Chronic Renal Failure

\section{Introduction}

Chronic Renal Failure (CRF) is a disease in which the function of kidney organ decreases until it is no longer able to work in filtering the remnants of the body's metabolism and the disposal of body electrolytes, as well as in maintaining fluid balance and body chemicals such as sodium and potassium in the blood or urine production (Vaidya \& Aeddula, 2019). In some serious cases, CRF patients are advised or given hemodialysis. However, the state of dependence of the patients on the hemodialysis can result in changes in biopsycho-socio-spiritual aspects, which most likely make the patients become weak and are unable to carry out activities as usual and helpless. As a consequence, they will be reluctant to meet with others, and withdraw from the social environment (Finnegan-John \& Thomas, 2012; Gerogianni \& Babatsikou, 2014).

Majority of CRF patients with hemodialysis suffer from depression (Shirazian et al., 2016). Depression is a form of natural disruption characterized by symptoms related to dysfunction of affect, emotions, thoughts and general activities. Depression also refers to a feeling of sadness and loss of interest in everything (Khan et al., 2019; Nur'aeni et al., 2019). Patients with depression generally exhibit distinctive psychological, physical and social symptoms, such as moodiness, prolonged sadness, sensitivity, irritability, loss of morale, lack of confidence, and decreased endurance (Khan et al., 2019; World Health Organization, 2020). Consequently, depression can exacerbate the effects of chronic disease and increase functional disability, make the act of dialysis no longer effective, and reduce the quality of life (Shirazian et al., 2016).

Based on our preliminary study with thirty CRF patients in one hospital in Indonesia, there were three people $(10 \%)$ had severe depression, six $(20 \%)$ with moderatesevere depression, five $(16.7 \%)$ with mildmoderate depression, $10(33.3 \%)$ with mild depression, and $6(20 \%)$ were normal. This indicates that the majority of CRF patients experienced mild to severe depression, which need immediate treatments. According to literature, depressed patients can be treated in the form of psychosocial therapy, such as cognitive therapy, interpersonal therapy, behavioral therapy, psychotherapy and group therapy, and life review therapy (American Psychological Association, 2020; Cuijpers et al., 2019). In this study, the author used cognitive therapy and life review therapy to reduce depression in CRF patients.

According to Sriwattanakomen et al. (2010), cognitive therapy is a therapy that identifies or recognizes negative and destructive thoughts. The therapy can help stop negative thought patterns and change them into positive ones as well as finding out the causes and controlling them (Derubeis et al., 2019; Skoog, 2011). Cognitive therapy is a form of psychotherapy that can train patients to change the way patients interpret and view things when the patients experience disappointment, so they feel better and can act more productively. It is given individually with the expectation that they are able to have healthy thoughts that can form adaptive coping in solving problems (Hayati et al., 2018; Skoog, 2011; Young et al., 2014). Previous studies have shown that the cognitive therapy is significant in reducing depression (Tanaka et al., 2011; Young et al., 2014).

Life review therapy, according to Wheeler (2013), is a retrospective review of existence, critical learning from a life or seeing for a person's past life by reawaking a life event into a more positive life story. Yi and Qunzhan (2019) said that life review therapy is an intervention related to the achievement of Erickson's psychosocial life stages with eight individual psychosocial stages, which individuals struggle to balance life conflicts to achieve successful life stages. This therapy makes individuals know how well they are to manage conflict and give meaning in each stage of life by integrating experiences in the present and the future. The result of this integration is self-acceptance, strong selfidentity and meaningful life (Yi \& Qunzhan, 2019). The process of life review consists of 4 interrelated parts, namely remembering, recalling, reviewing and rebuilding memory (Orozco et al., 2014). Several studies have examined the effectiveness of this therapy and proved significant in reducing depression (Ando et al., 2014; Lamers et al., 2015; Latorre et al., 2015; Townsend, 2014). 
Given the impacts of both therapies, it is assumed that the combination of those would be much more effective than one therapy only. Our review suggested there is no single study that has been conducted in both nationally and internationally in related to the combination of both cognitive and life review therapy. Therefore, the aim of this study was to determine the effect of the combination of cognitive and life review therapy compared with the life review therapy alone in reducing depression among CRF patients.

This study is significant for nursing science because depression in CRF patients is one of nursing problems that nurses should take care of. Nurses are not only focusing on physical condition of the patients, but also psychological, social and spiritual aspects of them. The findings of this study would be benefit for the nurses in the implementation of nursing intervention specifically in the hemodialysis units.

\section{Method}

This study employed a quasi-experimental research design with pretest and posttest with a comparison group. The population in this study was all patients with CRF undergoing hemodialysis at Raden Mattaher Jambi Hospital. The participants were selected using a consecutive sampling technique. The author chose this technique because the participants were only able to be reached in the hemodialysis units. Therefore, the participants who met the author during data collection were selected based on inclusion criteria until the required sample size was achieved. The inclusion criteria of the participants were: 1) patients with CRF undergoing hemodialysis therapy in hemodialysis units, 2) aged 1865 years, 3) patients with moderate-severe depression, 4) not experiencing a decrease in consciousness, communicative and cooperative (5) general conditions and vital signs before, during and after hemodialysis therapy showed stable conditions. There were 56 participants included in this study, which 28 were assigned in an experiment group and a comparison group.

To avoid bias, the two groups were selected from different units, which indicated that both groups were totally different. The sample selection was done first for the experiment group. After all participants were fulfilled, the author then selected participants for the comparison group using a matching method according to the participants' characteristics including age, gender, working status, marital status, education, duration of illness, administration of antihypertensive drugs, and frequency of hemodialysis. The number of participants was calculated using G-power 3.1 analysis program (Faul et al., 2009) at effect size d .8, $\square$ error probability .05 , statistical test power .8 , which resulted in a total sample of 52 as a minimum sample.

There were two instruments used in this study: 1) Instrument to collect demographic data, which consists of age, gender, working status, marital status, education, duration of illness, administration of antihypertensive drugs, and frequency of hemodialysis; 2) To measure depression, Beck Depression Inventory was used (Beck et al., 1988). The inventory consists of 21 questions. It is also available in the Indonesian version translated by Sakti (2009), with a validity and reliability of .748. However, for this study we also tested the validity with 30 respondents with $r$ value of .514 greater than $\mathrm{r}$ table. The inventory uses Likert scale, which the type of negative questions (unfavorable) with a choice of answers that have a range of values from 0 to 3 were only known by the researchers. Depression is interpreted by adding up all the respondents' answers and analyzing the results, which is then classified into 4 categories: normal (0-9), mild depression (10-15), moderate depression (16-30), severe depression ( $>30)$. The inventory was considered reliable using Cronbach's coefficient-alpha with a value of .710.

This study was conducted at Raden Mattaher Hospital in Jambi Indonesia for seven weeks, from April 21, 2017 to June 6, 2017. Data were collected by the researchers and assisted by four nurses in the hemodialysis units. Two nurses in the experiment group, and another two nurses in the comparison group. Prior to data collection, the author explained the research procedures to the nurses, and the author ensured that all nurses understood all processes. Pretest in each group was conducted right before the interventions were 
begun, and posttest was done right after the interventions were completed. There was no break between interventions and pretest or posstest.

The experiment group received the combination of cognitive therapy and life review therapy, while the comparison group was only given life review therapy. There was no difference in life review therapy provided in both experiment and comparison groups. The time for cognitive therapy was completely different from life review therapy. The cognitive therapy was implemented first, then followed by the life review therapy. Each meeting was based on an agreement between the researchers and the respondents in consideration of the physical condition of the patients during hemodialysis therapy. The cognitive therapy consists of four sessions carried out in four to five meetings or patient visits to undergo hemodialysis therapy. One meeting was held for about 50 minutes in the hemodialysis unit. While life review therapy consisted of four sessions conducted for 2530 minutes. This therapy was implemented every day in accordance with the agreed schedule. It was done in groups which were divided into four groups. Each group consisted of seven patients. The methods used in this therapy were discussion, question and answer, and instruction.

Descriptive statistics (mean, standard deviation) were used to describe demographic and depression data. As data were normally distributed, Dependent t-test was used to analyze the depression in each group before and after the intervention, and Independent t-test was used to analyze the difference in depression level after given intervention between the experiment group and the comparison group. The normality of the data was examined using Kolmogorov-Smirnov test with a result of $.93(>.05)$. Chi-square test was also used to examine the difference of the participants' characteristics between both groups.

This study was ethically approved by the Research Ethics Committee of Jambi University with approval number of 104 / UN18.5 / LT / 2017 on May 10, 2017. Prior to study, the author provided an explanation of the goals, processes and expectations of this study to all participants. Each participant was asked to sign an informed consent if they were willing to participate. Each participant was also given the full right to approve or refuse to join the study or withdraw at any time without any penalties. This study was conducted by upholding the ethical principles including autonomy, confidentiality, justice, honesty, non-maleficence.

\section{Results}

\section{Characteristics of Participants}

As shown in Table 1 , most of the participants were male $(32$, or $57 \%$ ), unemployed $(41$, or $73.2 \%$ ), having higher educational background (46, or $82,1 \%$ ), and married $(47$, or $83.9 \%)$. Of the total participants, 35 or $62.5 \%$ of the participants were given anti-hypertensive drugs. Chisquare test showed that there was no significant difference between the experiment group and the comparison group based on the characteristics of gender, working status, educational background, marital status and administration of anti-hypertensive drugs.

Table 2 shows that the average age of the participants was 48.73 years with the youngest age of 20 years and the oldest age of 65 years. The average length of illness was 26.50 months, and the average frequency of hemodialysis was 199.98 times. Based on the results of the independent t-test, there were no significant differences between the two groups based on the characteristics of age, duration of illness and frequency of hemodialysis $(\mathrm{p}>.05)$.

\section{Level of Depression Before and After Given Intervention}

Table 3 shows that there was no significant difference in the depression level during pretest $(p=.175)$, which indicated that both groups had the same baseline data. Based on the Dependent-t-test, there was a significant difference in the level of depression in the experiment group before and after the intervention $(\mathrm{p}<.01)$. But there was no significant difference in the level of depression before and after the intervention in the comparison group $(\mathrm{p}=.485)$. Based on the results of the Independent t-test, there 
Sutinah: Effect of Life Review and Cognitive Therapy on Depression in Patients with Chronic Renal Failure

Table 1 Characteristics of Participants According to Gender, Working Status, Educational Background, Marital Status, and Administration of Anti-Hypertension Drug

\begin{tabular}{|c|c|c|c|c|c|c|c|}
\hline \multirow[t]{2}{*}{ Characteristics } & \multicolumn{2}{|c|}{$\begin{array}{l}\text { Experiment } \\
\quad(\mathrm{n}=\mathbf{2 8})\end{array}$} & \multicolumn{2}{|c|}{$\begin{array}{c}\text { Comparison } \\
(\mathrm{n}=28)\end{array}$} & \multicolumn{2}{|c|}{$\begin{array}{c}\text { Total } \\
(\mathbf{n}=\mathbf{5 6})\end{array}$} & \multirow[t]{2}{*}{ p-value } \\
\hline & $\mathbf{n}$ & $\%$ & $\mathbf{n}$ & $\%$ & $\mathrm{n}$ & $\%$ & \\
\hline \multicolumn{8}{|l|}{ Gender } \\
\hline Male & 16 & 57.1 & 16 & 57.1 & 32 & 57.1 & 1.000 \\
\hline Female & 12 & 42.9 & 12 & 42.9 & 24 & 42.9 & \\
\hline \multicolumn{8}{|l|}{ Working Status } \\
\hline Working & 7 & 25 & 8 & 28.5 & 15 & 26.8 & 0.763 \\
\hline Not working & 21 & 75 & 20 & 71.5 & 41 & 73.2 & \\
\hline \multicolumn{8}{|c|}{ Educational Background } \\
\hline $\begin{array}{l}\text { Elementary and } \\
\text { Junior high }\end{array}$ & 3 & 10.7 & 7 & 25 & 10 & 17.9 & 0.163 \\
\hline $\begin{array}{l}\text { Senior high } \\
\text { school and } \\
\text { University level }\end{array}$ & 25 & 89.3 & 21 & 75 & 46 & 82.1 & \\
\hline \multicolumn{8}{|l|}{ Marital Status } \\
\hline Married & 24 & 85.7 & 23 & 82.1 & 47 & 83.9 & 0.716 \\
\hline Not married & 4 & 14.3 & 5 & 17.9 & 9 & 16.1 & \\
\hline \multicolumn{8}{|c|}{ Administration of Anti-Hypertension Drug } \\
\hline Yes & 19 & 67.9 & 16 & 57.1 & 35 & 62.5 & 0.408 \\
\hline No & 9 & 32.1 & 12 & 42.9 & 21 & 37.5 & \\
\hline
\end{tabular}

Table 2 Characteristics of Participants Based on Age, Duration of Illness, and Frequency of Hemodialysis

\begin{tabular}{lcccccc}
\hline Characteristics $\quad$ Group & Mean & SD & Min-Max & $\mathbf{9 5 \% C I}$ & $\mathbf{t}$ & P-Value \\
\hline Age (year) & 46.93 & 12.534 & $20-65$ & $42.07-51.79$ & -1.094 & 0.279 \\
$\begin{array}{l}\text { Experiment } \\
\text { Comparison }\end{array}$ & 50.54 & 12.127 & $21-65$ & $45.83-55.24$ & & \\
\multicolumn{1}{c}{ Total } & 48.73 & 12.355 & $20-65$ & $45.42-52.04$ & & \\
$\begin{array}{l}\text { Duration of IIIness } \\
\text { (month) }\end{array}$ & 20.89 & 18.990 & $2-65$ & $13.53-28.26$ & -0.785 & 0.436 \\
$\begin{array}{l}\text { Experiment } \\
\text { Comparison }\end{array}$ & 32.11 & 60.975 & $4-312$ & $8.46-55.75$ & & \\
\multicolumn{1}{c}{ Total } & 26.50 & 45.102 & $2-312$ & $14.42-38.58$ & & \\
$\begin{array}{l}\text { Frequency of } \\
\text { Hemodialysis }\end{array}$ & 164.86 & 152.01 & $11-521$ & $105.21-223.80$ & -0.726 & 0.471 \\
$\begin{array}{l}\text { Experiment } \\
\text { Comparison }\end{array}$ & 235.11 & 488.67 & $19-2496$ & $45.62-424.60$ & & \\
\multicolumn{1}{c}{ Total } & 199.98 & 360.32 & $11-2496$ & $103.49-296.48$ & & \\
\hline
\end{tabular}


Sutinah: Effect of Life Review and Cognitive Therapy on Depression in Patients with Chronic Renal Failure

Table 3 Level of Depression Before and After Given Intervention in the Experiment and Comparison Group

\begin{tabular}{lccccc}
\hline \multirow{2}{*}{ Group } & \multicolumn{2}{c}{ Depression } & \multirow{2}{*}{$\begin{array}{c}\text { Mean } \\
\text { difference (SD) }\end{array}$} & t & p-value \\
\cline { 2 - 3 } & \multicolumn{2}{c}{ Pretest } & Posttest & & \\
\cline { 2 - 3 } & Mean (SD) & Mean (SD) & & & \\
\hline Experiment & $27.04(4.71)$ & $22.29(4.24)$ & $4.75(.47)$ & 8.820 & $<.001^{\mathrm{a}}$ \\
Comparison & $26.54(4.18)$ & $26.71(3.70)$ & $-.17(.35)$ & -0.708 & $0.485^{\mathrm{a}}$ \\
p-value & $0.175^{\mathrm{b}}$ & $0.001^{\mathrm{b}}$ & & & \\
\hline adependent t-test & ${ }^{D}$ Independent t-test
\end{tabular}

was a significant difference in the level of depression after the intervention between both groups, which indicated that the therapy in the experimental group was significantly effective at reducing depression level than the therapy in the comparison group $(\mathrm{p}=.001)$.

\section{Discussion}

Findings of this study revealed that the combination of cognitive and life review therapy had a significant effect in reducing depression level compared with the life review therapy alone. The significant effect of the combination of cognitive and life review therapy in the experimental group could be seen from the difference of the average of depression level between pretest and posttest, with mean of 4.75 and standard deviation of $.47(\mathrm{p}<.01)$. Contrarily, the life review therapy alone in the comparison group did not provide any effects on depression level $(\mathrm{p}=.485)$; in fact, there was a slight increase of depression level from 26.54 to 26.71 as indicated in our study. This might be due to the negative feelings during and after life review therapy that might take time to heal among participants. Each participant might response differently after discussing their lives, which needs to be anticipated. This result however provides the new knowledge in alternative medicine and adult nursing.

Both therapies have different roles, which cognitive therapy focuses on identification of negative thoughts and their causes as well as controlling them to be positive (Derubeis et al., 2019; Skoog, 2011), while life review therapy focuses on changing the negative feelings by acceptance, restoration of self, and resolution of grief(Yi \& Qunzhan, 2019). Thus, the combination of both are effective in reducing depression, as indicated in our study.

In addition, this result was in line with the theory outlined by Townsend (2015) who said that the process of implementing cognitive therapy and life experience review therapy is a therapy that is oriented towards the goal of solving patient problems. At the beginning of the meeting, the therapist must identify the problems facing the patient. Then together set goals and expected results in therapy. The process of discussion in solving problems faced by patients is needed when patients begin to recognize cognitive distortion and improve their thinking patterns.

Our results also indicated that the life review therapy alone had no significant effect on depression. This result against the findings from previous studies revealed that there was a significant effect of the single life review therapy on depression (Ando et al., 2014; Lamers et al., 2015; Latorre et al., 2015; Townsend, 2014). According to our study, the life review therapy will be effective if combined with cognitive therapy.

Our study has implications in nursing practice specifically in Indonesia. Most of nursing services especially in the hemodialysis units rarely address the psychosocial aspects of their patients. This can be seen from the format of nursing assessment that only covers physical aspects before, during and after the implementation of hemodialysis therapy. The results of our study suggest that the hemodialysis units should add one assessment dimension, namely the psychosocial aspect of the patients along with the action plan in the form of nursing care standards. In addition, mental health services in the hemodialysis units can be developed with the intervention of mental nursing in CRF patients who undergo routine hemodialysis therapy. Additionally, this 
Sutinah: Effect of Life Review and Cognitive Therapy on Depression in Patients with Chronic Renal Failure

study also suggests that the roles of mental health nurses in the hemodialysis units are necessary in reducing depression of $\mathrm{CRF}$ patients, and the combination of cognitive and life review therapy serves as an input for nursing intervention in the units.

The limitation of this study might include the implementation of the interventions which varied among participants dependent on the physical condition of each participant after hemodialysis. Some participants might be strong enough to join, some might not, which might influence the outcomes of the findings. However, the use of the comparison group in this study might reduce the bias. In addition, the time for data collection, specifically for posttest might need little bit more time to adjust the feelings of each individual after the life review therapy. Future studies may need to focus on this factor for consideration. In addition, the results of this study were also limited to chronic renal failure patients undergoing hemodialysis therapy in one hospital which may not be generalized. However, this research can be a reference for conducting research in the same area. To understand depression in patients, different research methods, such as cohort or qualitative study need to be done. Also, to determine the effect of cognitive therapy alone is needed for comparison.

\section{Conclusion}

It is concluded that the combination of life review and cognitive therapy was significantly effective in reducing depression. Therefore, this therapy is recommended as a part of nursing interventions particularly for the treatment of depression among the patients with chronic renal failure undergoing hemodialysis. The use of life review and cognitive therapy as the additional components of the medical treatment will reflect such a holistic care for the patients in hemodialysis units.

\section{References}

American Psychological Association. (2020). Overcoming depression: How psychologists help with depressive disorders. Retrieved October 2, 2019 from https://www.apa.org/ helpcenter/depression

Ando, M., Sakaguchi, Y., Shiihara, Y., \& Izuhara, K. (2014). Universality of bereavement life review for spirituality and depression in bereaved families. American Journal of Hospice and Palliative Medicine, 31(3), 327-330. https://doi. org/10.1177/1049909113488928

Beck, A. T., Steer, R. A., \& Carbin, M. G. (1988). Psychometric properties of the Beck Depression Inventory: Twenty-five years of evaluation. Clinical psychology review, 8(1), 77-100. https://doi.org/10.1016/02727358(88)90050-5

Cuijpers, P., Quero, S., Dowrick, C., \& Arroll, B. (2019). Psychological treatment of depression in primary care: Recent developments. Current Psychiatry Reports, 21(12), 129. https://doi.org/10.1007/s11920019-1117-x

DeRubeis, R. J., Webb, C. A., Tang, T. Z., \& Beck, A. T. (2019). Cognitive therapy. In K. S. D. D. J. A. Dozois (Ed.), Handbook of Cognitive-behavioral therapies (pp. 218248). The Guilford Press.

Faul, F., Erdfelder, E., Buchner, A., \& Lang, A.-G. (2009). Statistical power analyses using $G^{*}$ Power 3.1: Tests for correlation and regression analyses. Behavior Research Methods, 41(4), 1149-1160. https://doi. org/10.3758/brm.41.4.1149

Finnegan-John, J., \& Thomas, V. J. (2012). The psychosocial experience of patients with end-stage renal disease and its impact on quality of life: findings from a needs assessment to shape a service. International Scholarly Research Notices, 2013. https:// doi.org/10.5402/2013/308986

Gerogianni, S. K., \& Babatsikou, F. P. (2014). Social aspects of chronic renal failure in patients undergoing haemodialysis. International Journal of Caring Sciences, 7(3), 740-745. 
Sutinah: Effect of Life Review and Cognitive Therapy on Depression in Patients with Chronic Renal Failure

Hayati, U. F., Fatimah, S., \& Mardhiyah, A. (2018). Comparative effectiveness of cognitive behavioral therapy 5 sessions and 12 sessions toward to post traumatic stress disorder on post flood disaster adolescent. Jurnal Keperawatan Padjadjaran, 6(1), 3749. https://doi.org/10.24198/jkp.v6i1.357

Khan, A., Khan, A. H., Adnan, A. S., Sulaiman, S. A. S., \& Mushtaq, S. (2019). Prevalence and predictors of depression among hemodialysis patients: a prospective follow-up study. BMC Public Health, 19(531). https://doi.org/10.1186/s12889019-6796-z

Lamers, S. M. A., Bohlmeijer, E. T., Korte, J., \& Westerhof, G. J. (2015). The efficacy of life-review as online-guided self-help for adults: a randomized trial. Journals of Gerontology Series B: Psychological Sciences and Social Sciences, 70(1), 24-34. https://doi.org/10.1093/geronb/gbu030

Latorre, J. M., Serrano, J. P., Ricarte, J., Bonete, B., Ros, L., \& Sitges, E. (2015). Life review based on remembering specific positive events in active aging. Journal of Aging and Health, 27(1), 140-157. https:// doi.org/10.1177/0898264314541699

Nur'aeni, A., Mirwanti, R., Anna, A., \& Nurhidayah, I. (2019). Determinant factors of depression in patients with coronary heart disease. Jurnal Keperawatan Padjadjaran, 7(3), 246-254. https://doi.org/10.24198/jkp. v7i3.1194

Orozco, G. L., Wanda, M. L. L., Blando, J. A., \& Shooshani, B. (2014). Introduction to multicultural counseling for helping professionals ( $3 \mathrm{rd}$ ed.). Routledge.

Sakti, E. P. (2009). Pengaruh terapi kognitif perilaku untuk menurunkan depresi pada penderita diabetes mellitus. [Master's thesis, Universitas Katolik Soegijapranata] Unika Soegijapranata Repository. Retrieved December 13, 2019, from http://repository. unika.ac.id/3968/

Shirazian, S., Grant, C. D., Aina, O., Mattana, J., Khorassani, F., \& Ricardo, A. C. (2016).
Depression in chronic kidney disease and end-stage renal disease: Similarities and differences in diagnosis, epidemiology, and management. Kidney International Reports, 2(1), 94-107. https://doi.org/10.1016/j. ekir.2016.09.005

Skoog, I. (2011). Psychiatric disorders in the elderly. The Canadian Journal of Psychiatry, 56(7), 387-397. https://doi. org/10.1177/070674371105600702

Sriwattanakomen, R., McPherron, J., Chatman, J., Morse, J. Q., Martire, L. M., Karp, J. F., . . Stack, J. A. (2010). A comparison of the frequencies of risk factors for depression in older black and white participants in a study of indicated prevention. International Psychogeriatrics, 22(8), 1240-1247. https:// dx.doi.org/10.1017\%2FS1041610210001523

Tanaka, H., Sasazawa, Y., Suzuki, S., Nakazawa, M., \& Koyama, H. (2011). Health status and lifestyle factors as predictors of depression in middle-aged and elderly Japanese adults: a seven-year follow-up of the Komo-Ise cohort study. BMC Psychiatry, 11(1), 20. https://doi.org/10.1186/1471244x-11-20

Townsend, M. C. (2014). Psychiatric mental health nursing: Concepts of care in evidencebased practice. FA Davis.

Townsend, M. C. (2015). Essentials of psychiatric mental health nursing: Concepts of care in evidence-based practice (3rd ed.). FA Davis Company.

Vaidya, S. R., \& Aeddula, N. R. (2019). Chronic Renal Failure StatPearls. StatPearls Publishing.

Wheeler, K. (2013). Psychotherapy for the advanced practice psychiatric nurse: $A$ how-to guide for evidence-based practice. Springer Publishing Company.

World Health Organization. (2020). Depression. Retrieved October 14, 2019, from https://www.who.int/news-room/factsheets/detail/depression 
Sutinah: Effect of Life Review and Cognitive Therapy on Depression in Patients with Chronic Renal Failure

Yi, F., \& Qunzhan, Z. (2019). The Effect of life review on depression and depressive symptoms in adults: A descriptive literature review. [Master's thesis, Lishui University] Nursing Department, Medicine, and Health College, Lishui University, China, China.
Young, J. E., Rygh, J. L., Weinberger, A. D., $\&$ Beck, A. T. (2014). Cognitive therapy for depression. In D. H. Barlow (Ed.), Clinical handbook of psychological disorders: A stepby-step treatment manual, 5th ed. (pp. 275331). The Guilford Press. 